\title{
Learning-by-Doing Spillovers in the Semiconductor Industry
}

\section{Douglas A. Irwin and Peter J. Klenow}

University of Chicago

The semiconductor industry is often cited as a "strategic" industry in part because important learning-by-doing spillovers may justify special industrial policies. Documenting the precise nature of these spillovers is crucial for determining the advisability of such policies and is helpful for understanding the contribution of learning to endogenous growth. Yet existing empirical evidence on learning by doing in semiconductor production is scant and evidence on spillovers is nonexistent. Using quarterly, firm-level data on seven generations of dynamic random access memory (DRAM) semiconductors over 1974-92, we find that (a) learning rates average 20 percent, (b) firms learn three times more from an additional unit of their own cumulative production than from an additional unit of another firm's cumulative production, $(c)$ learning spills over just as much between firms in different countries as between firms within a given country, (d) Japanese firms are indistinguishable from others in learning speed, and $(e)$ intergenerational learning spillovers are weak, being marginally significant in only two of seven DRAM generations.

\section{Introduction}

Modern economic analysis of learning by doing-the decline in production costs resulting from greater experience with the production process, typically measured by cumulative output-dates from the

We are indebted to the Center for International Business Education and Research in the Graduate School of Business of the University of Chicago for financial support. Irwin gratefully acknowledges funding from the James S. Kemper Foundation Faculty Research Fund and Klenow from the National Science Foundation. We wish to thank Kenneth Flamm, Randy Mariger, two referees, and numerous workshop participants for helpful comments. 
early 1960s with theoretical work by Arrow (1962) and empirical evidence from Alchian (1963). ${ }^{1}$ Subsequent research helped establish a key distinction between internal and external learning. Learning by doing that is purely internal to the firm, wherein each firm must undertake production itself to reap the cost savings, generates dynamic economies of scale comparable in effect to static economies of scale. If some or all of the knowledge arising from learning also spills over to other firms in the industry, however, then learning by doing generates an external economy and firms may underproduce relative to what is socially efficient.

In this paper, we examine learning by doing as a feature of the semiconductor industry. Despite frequent and prominent allegations that both internal and external learning exists, the semiconductor industry remains among the least studied by economists using systematic empirical evidence. Our attention is directed to the semiconductor industry for several reasons. First, semiconductors are an important input to several high-technology industries. Along with the suspicion that knowledge spillovers are pervasive within this sector, many observers conclude that the semiconductor industry is a "strategic" industry. ${ }^{2}$ This distinctiveness has been the justification for special government trade and industrial policies for semiconductors, particularly as international competition with Japan has intensified. ${ }^{3}$ Japanese industrial policy, it is frequently argued, enabled Japanese firms to descend the learning curve more rapidly and consequently displace once dominant U.S. producers. Japanese preeminence in semiconductors has created the widespread concern that U.S. firms will not have the necessary production experience to compete in future generations of semiconductors, perhaps even to the detriment of domestic downstream users of semiconductors such as computer manufacturers.

${ }^{1}$ For more recent theoretical contributions, see Spence (1981), Fudenberg and Tirole (1983), and Ghemawat and Spence (1985). Zimmerman (1982) and Lieberman (1984) are representative of the more recent empirical industry studies.

${ }^{2}$ A working group of the National Research Council (1992, p. 85), e.g., writes that "the working group believes that the semiconductor industry, a vital upstream segment of the crucial information industries, is a 'strategic industry' essential to the nation's well being." The National Advisory Committee on Semiconductors (1992, pp. 2-4) states that "strong linkages [within the microelectronics industry] help to create external economieseconomic benefits that flow between semiconductor firms and their customers and suppliers, and also between competing semiconductor firms. . . . The critical importance of semiconductors to U.S. economic growth and international competitiveness demands a new and coordinated strategic response from the industry . . . and the Federal Government."

${ }^{3}$ The U.S. government, e.g., has subsidized Sematech, an industry research and development consortium. For an empirical analysis of the effects of Sematech, see Irwin and Klenow (1994). 
Second, the semiconductor industry is well suited for examining recent theories of endogenous growth that emphasize learning-bydoing spillovers as generating sustained increases in income and as explaining growth performances across countries. Knowledge spillovers are central to the Romer (1986), Lucas (1988), Aghion and Howitt (1992), and Grossman and Helpman (1992) growth models and take the specific form of external learning by doing in Lucas (1988, 1993), Stokey (1988), and Young (1991, 1993). Stokey stresses that learning contributes to growth if experience with the current generation of products is especially helpful for producing more advanced products, a link that successive generations of semiconductors allow us to examine. The international character of the semiconductor industry makes it useful for assessing Lucas's (1988) model wherein within-country learning spillovers explain the diversity of observed growth rates and income levels across countries. Evidence on the speed of learning in semiconductors will help us gauge its contribution to growth, thereby providing evidence on Lucas's (1993) conclusion that learning by doing is a prime candidate to explain the incredible growth observed, for example, in South Korea over the last three decades.

Despite the widespread attention that semiconductors have received in policy discussions of strategic high-technology industries and growth-related knowledge spillovers, the ratio of anecdote to evidence about the semiconductor industry-to paraphrase George Stigler-remains remarkably high. ${ }^{4}$ In this paper, we test a number of hypotheses that are frequently mentioned in the context of this industry. Section II summarizes several popular but competing claims made about learning-by-doing spillovers in the semiconductor industry, and Section III discusses the limited extent to which existing empirical research has addressed these claims. In Section IV we present our estimates of learning-by-doing spillovers in the semiconductor industry. We employ quarterly data for 1974-92 on shipments by all merchant firms for seven generations of dynamic random access memory (DRAM) chips. We examine whether the benefits of learning by doing remain solely within the firm, or whether there are significant spillovers of either national or international consequence, focusing in particular on the similarities and differences between United States and Japan-based firms. We also address whether learning spillovers are evident across product generations of DRAMs.

\footnotetext{
${ }^{4}$ As Stigler wrote in the preface to The Organization of Industry (1968), "The ratio of hypothesis to reasonably persuasive confirmation is distressingly high in all economic literature, and it must be my chief if meager defense that I am not the worst sinner in the congregation."
} 
To anticipate our conclusions, we find a learning rate of roughly 20 percent in various generations of DRAMs. We find strong evidence that firms internalize the substantial component of learning, although international (not strictly national) learning spillovers are evident. On average, the marginal contribution of a firm's own cumulative output to the cost reduction is three times the marginal contribution of world cumulative output. We find no evidence that Japanese firms enjoy steeper learning curves than their competitors elsewhere. We find limited intergenerational learning spillovers in two DRAM products, but no significant effects in five generations, including the last two.

\section{Hypotheses about the Semiconductor Industry}

A large case study and policy-oriented literature about the semiconductor industry exists, stimulated in part by the trade friction with Japan in high-technology products. This descriptive literaturewritten by economists, political scientists, government agencies, industry analysts, consultants, and others-contains a veritable cornucopia of testable hypotheses about the industry.

The most prominent "stylized fact" about the semiconductor industry is that unit costs fall significantly as production experience (cumulative output) rises. Because semiconductors can be produced only with exacting standards of precision and cleanliness, the production process can be fine-tuned with the information gathered from successive production runs. Specifically, learning by doing takes the form of ever-increasing "yields," that is, ever-increasing percentages of usable semiconductor chips, as cumulative output rises. For example, early in the product cycle of a semiconductor, as much as 90 percent of output is flawed or nonfunctioning and must be discarded; once greater production experience has been acquired, this failure rate can fall to under 10 percent. ${ }^{5}$ This discarded output is costly: according to the Organization for Economic Cooperation and Development (1985, p. 123), roughly 80 percent of the cost of making $64 \mathrm{~K}$ DRAM chips in 1982 arose from yield factors.

The rate of learning by doing is sometimes thought to differ by country. Indirect evidence that the learning curve is steeper for Japanese firms comes from Finan and Amundsen (1986, pp. 316-18), who argue that more rapid cost reduction via learning accounts for Japan's market share in DRAMs. Calibrating a model to market data, they contend that both U.S. and Japanese firms began early $16 \mathrm{~K}$

\footnotetext{
${ }^{5}$ Strictly speaking, this learning may not be a pure by-product of experience, but may require the joint input of managerial monitoring.
} 
DRAM production in 1978 with a yield of about 2 percent; by 1982 Japanese yields had increased to 39 percent whereas U.S. yields were just 26 percent, despite the fact that Japan had a smaller market share. On the other hand, the Semiconductor Industry Association (1983, p. 44) maintains that "there is evidence that Japanese firms' costs do not decline more rapidly than those of U.S. firms as cumulative output increases." 6

Standard accounts suggest that firms are able to appropriate much of their learning: "although some learning readily becomes general knowledge and thus a public good, much is either uniquely applicable to a particular operation or can be transferred to another facility only with technical assistance from the firm having the know-how. Consequently, a large portion of the benefits produced by learning accrues to the firms doing the learning" (Tilton 1971, p. 86). ${ }^{7}$

That the firm can internalize the benefits of learning does not clarify whether these benefits are plant-specific or can be transferred within the firm between plants, and both views have been asserted. In a study of the Japanese semiconductor industry, Kimura (1988, p. 50) contends that "the learning economies . . . are only partially transferable across plants and across firms as the yields often depend on specific conditions of fabrication processes of a particular plant." In contrast, engineers at International Business Machines (IBM) observe that production experience is transferable across its plants. Stapper et al. (1982, p. 541) note that

The achievement of high yield in any of the plants is immediately shared within IBM. A manufacturing innovation causing a yield breakthrough in any one location is adapted very quickly by other manufacturing lines. ... For example, yield detractors occurring in the manufacture of the 64K-bit memory chip are reviewed periodically between the Sindelfingen plant and the Burlington plant. The capability of measuring the yield components has made it possible to minutely compare the differences between the two locations. As a consequence of these exchanges (and hard work on both sides of the ocean) the yield at both locations has increased and has resulted in consistently high computer memory productivity.

\footnotetext{
${ }^{6}$ The association cites a 1979 Japanese study that estimates that unit costs of semiconductor firms in Japan fell by 25 percent for each doubling of cumulative volume. This figure is not much different from the 28 percent commonly cited for U.S. firms.

${ }^{7}$ Baldwin and Krugman (1988, p. 176), e.g., maintain that "the details of manufacture, as learned over time in the process of gaining experience, are . . . highly appropriable."
} 
Even if the firm can appropriate much of the benefits of learning, it is commonly asserted that there is a spillover in that at least part of the benefit of one firm's learning can be captured by others in the industry. Some argue that learning spills over mainly to other firms within the country. Industry lore from Silicon Valley holds that informal contacts and the significant degree of mobility among engineers and other skilled personnel within the U.S. semiconductor industry ensure that production experience is transferable to other national firms.

In Japan, by contrast, the mobility of skilled labor between firms is more limited than in the United States. ${ }^{8}$ Yet national spillovers are thought to have arisen from government-sponsored cooperative research and other formal and informal ties between firms. In the $1970 \mathrm{~s}$ and early 1980s, government-owned Nippon Telegraph and Telephone (NTT) transferred device designs and production technology of $64 \mathrm{~K}$ and $256 \mathrm{~K}$ DRAMs to other Japanese firms, allowing them access to the knowledge at little cost. Okimoto (1989, p. 74) writes that "Japan's capacity to overwhelm U.S. manufacturers of mass memory chips has been due in no small measure to joint research conducted by NTT family firms with NTT and the diffusion of NTT technology. . . . Japanese manufacturers could not have come from so far behind in such a short time without NTT's diffusion of technology." Various other formal and informal links between firms in Japan purportedly facilitate the transfer of knowledge.

If within-country spillovers are present, it is hard to imagine that all such knowledge can be confined solely within the country. Therefore, a related hypothesis is that knowledge within the industry is so easily obtained that learning is international in scope. Though some details of manufacturing may be highly appropriable by the firm, Baldwin and Krugman (1988, p. 176) argue that "the ability of firms to learn from each other is not noticeably restricted by national boundaries." Communication between firms may be facilitated by foreign direct investments. Okimoto et al. $(1984$, p. 76$)$ suggest that cross-border investments by U.S. and Japanese firms mean that "by the mid-1980s as much as 50 percent of each country's VLSI [very large scale integration] products might be produced in the other, and each country's industry would be able to draw on the other country's strengths to overcome its own weaknesses."

But it is sometimes argued that international spillovers are one-

8 "Japan's lifetime employment system, even though it is not as widespread among workers in the semiconductor industry as many assume, ensures a relatively low rate of turnover and produces a strong sense of identification with the company" (Okimoto, Sugano, and Weinstein 1984, p. 60). 
sided: Japanese firms can learn from U.S. firms, but U.S. firms are unable to learn from Japanese firms. Throughout the 1960s and 1970s, Japan acquired a substantial amount of U.S. technology from license agreements with major U.S. firms that were prevented from investing directly in Japan. Some believe that a one-way flow of technology continues today because of the openness of U.S. society and the lack of investment restrictions. According to the National Research Council (1992, p. 51), "Equity investments presumably give Japanese investors direct, first-hand access to state of the art technology" and "the openness of the U.S. semiconductor industry to foreign investment and the appropriability of American know-how have caused the private and public sectors to be concerned about how to monitor and, where necessary, to restrict foreign investments."9

In Japan, by contrast, various formal and informal barriers, such as investment restrictions and the closed nature of the industry to outsiders, supposedly prevent U.S. firms from acquiring information on Japanese production technology. In Japan there is "an unwillingness to license proprietary production technologies that emerge from either government-coordinated or individual firm R \& D. . . It appears, either as a matter of MITI [Ministry of International Trade and Industry] policy or industry choice, that U.S. firms are being denied access to proprietary production technologies that emerged from the VLSI project and are being made available to Japanese firms" (Borrus, Millstein, and Zysman 1982, p. 109). Thus Borrus, Tyson, and Zysman (1986, p. 111) argue that "critically important spillovers are indeed generated in this industry, and in Japan's case policy and industry structures combine to keep them isolated from diffusing internationally."

Another question is whether learning spillovers occur across generations of semiconductor chips. A common claim is that certain semiconductors-especially high-volume, homogeneous commodity chips such as DRAMs - are "technology drivers" in that learning by doing lowers costs in subsequent generations of memory and other chips. A report from the Federal Interagency Staff Working Group (1987, p. 57) on semiconductors states that "the benefits of such learning are not confined to single generations of single chips. ... Such transfer of learning from a 'technology driver' to another chip can result in better starting yields, faster yield improvement, and often improved final yields when the learning process on the new chip is complete." The

${ }^{9}$ The National Research Council also writes that "a troublesome disconnect between microlevel incentives for individual U.S. firms (which want and need to attracl capital) and the collective, potentially adverse, long-term impact of Japanese investments on the U.S. semiconductor industry as a whole, may result in a continuing net transfer of vital technologies from the United States" (p. 51). 
Semiconductor Industry Association (1983, p. 59) states that "dynamic RAMs are the 'bellwether for the industry' - the product that enables firms to reduce costs and enhance production in virtually all other semiconductor product lines." This assumption reinforces concerns about Japanese industrial targeting - that a temporary subsidy to capture dominance in one generation of DRAMs might permanently shift advantage to Japanese semiconductor producers in future generations of DRAMs and other chips. ${ }^{10}$ Kimura (1988, p. 50 ), however, argues that "the learning economies tend to be product specific because the fabrication process required for one device differs from that for another, and because the photomasksimprovement in which often results in substantial improvement of the yield-are product specific."

Are there learning-by-doing spillovers in semiconductor production, or is learning internalized within the firm? If there are spillovers, are they important and are they international in nature? Are Japanese producers really "different" from those in other countries, and how significant are intergenerational learning effects? All these accounts about the semiconductor industry are testable hypotheses, but what evidence has been brought to bear on them?

\section{Industry Evidence from Previous Studies}

Despite the abundance of varying and sometimes contradictory claims about the semiconductor industry, there is a paucity of empirical evidence on the crucial question of learning-by-doing spillovers. Virtually the only consensus that currently exists from various empirical studies of the semiconductor industry is that learning by doing is indeed a feature of production.

A well-accepted "stylized fact" about semiconductors is that the slope of the learning curve is .28; that is, unit production costs fall by 28 percent every time cumulative output doubles. This figure is frequently accepted as the best point estimate of learning. In their simulation study of semiconductor trade policies, Baldwin and Krugman (1988) take the 28 percent figure as a parametric condition of 16K DRAM production, citing a report published in 1983 by the Office of Technology Assessment. This report states that "learning curves typical of IC [integrated circuit] manufacture show that when cumulative production doubles, costs decrease by about 28 percent"

${ }^{10}$ This is true only if the purported intergenerational spillover is internal to the firm. However, Baldwin and Krugman (1988, p. 176) suggest that "the basic innovations involved in passing from one generation to the next in RAMs are relatively hard to appropriate." 
(p. 76). The report in turn cites as its source an article in Business Week from 1974 and a Commerce Department study from 1979. The U.S. Department of Commerce $(1979$, p. 50$)$ arrived at this figure using annual observations for 1964-75 of aggregate integrated circuit output based on data presented in a Morgan Stanley Electronics newsletter in 1976. Over this time period, a doubling of cumulative units was associated with an average 28 percent decline in the constant-dollar average price. ${ }^{11}$

Needless to say, important questions can be raised about the meaning of raw correlations of average (constant-dollar) industry price and total output, with no other variables controlled for. These data presumably apply to U.S. production alone, although this is not explicitly stated. This could overstate the speed of learning to the extent that it ignores Japanese and European production. Furthermore, the figures are based on data from the 1960s and early 1970s, when semiconductor technology was still in its infancy; indeed, the last observation was nearly 20 years ago. The data also provide no assurance that the learning curves are comparable across different products.

Regression results, rather than simple period averages, have also been used to estimate learning parameters. A typical specification is

$$
p_{t} \approx c_{t}=e^{a} \cdot\left(Q_{t-1}\right)^{\gamma} \cdot e^{\varepsilon_{t}},
$$

where $p_{t}$ is the price, $c_{t}$ is every firm's marginal cost, and $Q_{t-1}$ is the industry's lagged cumulative output. After logs are taken, the following regression is estimated:

$$
\ln p_{t}=a+\gamma \ln Q_{t-1}+\varepsilon_{t} .
$$

This specification usually generates $R^{2}$ 's of about .98 and $t$-statistics on $\gamma$ of over 10.

A Federal Trade Commission study published in 1977 took nine observations of annual data (1964-72) on digital integrated circuits and regressed average cumulative revenue on a constant term and cumulative U.S. production volume. Webbink (1977, p. $50 \mathrm{ff}$.) reports a coefficient of -0.40 on cumulative production, indicating that a doubling of cumulative volume corresponds to a 24 percent fall in cumulative average revenue. Dick (1991, pp. 142-43) reports regressions of industry price on lagged cumulative production (an aggregate of U.S. and Japanese firms) of $1 \mathrm{~K}$ and $4 \mathrm{~K}$ DRAMs using annual data for 1974-80 (seven observations) and 1976-81 (six observations), respectively. He finds a 19 percent learning curve in $1 \mathrm{~K}$ DRAM production and a 7 percent learning curve in $4 \mathrm{~K}$ DRAM production.

${ }^{11}$ These data link a price decline to cumulative output, and the Commerce study interpreted the declining price as reflecting declining cost. 
Gruber (1992) estimates similar equations for DRAMs, EPROMs (erasable programmable read-only memories), and SRAMs (static random access memories) but finds no significant learning for DRAMs if current output and time are included.

These studies implicitly assume that dynamic marginal cost is equal to static marginal cost over the product cycle. However, learning by doing implies that dynamic marginal cost will be lower than true marginal cost, how much lower depending on the scale of future production and the extent of diminishing returns to accumulated production experience. Aside from this issue, most studies of learning by doing use the market price as a proxy for marginal cost because cost data by firm are not available. This assumes that price-cost margins are constant over time, price-cost margins change in a way controlled for by other variables, or changes in the margin are small in relation to changes in marginal cost. Yet given the dramatic changes in competition over the product cycle-each generation is introduced by a leading firm that often faces up to 20 competitors later onprice-cost margins might decline steeply as the product matures. ${ }^{12}$

These specifications also assume that there are no other serially correlated supply shocks with important effects on price, such as changes in input prices, $\mathrm{R} \& \mathrm{D}$ spending, and exogenous technical progress (either deterministic or stochastic). Because output data by firm are not utilized, the standard specification also cannot address the issue of internal versus external learning by doing.

Flamm (1993a, pp. 66-69) attempts to control for variations in installed capital across firms, but because of the unavailability of data on the capital stock by each DRAM producer, he chooses a period in which firms were thought to be operating at full capacity. In this case, capital can be represented by a firm-specific coefficient in the following regression:

$$
\ln q=a_{i}+\epsilon \ln Q+b_{i} \ln \left(\frac{1}{Q}\right)+\varepsilon,
$$

where $a_{i}$ and $b_{i}$ vary by firm. Employing quarterly data for one year (1988:3-1989:2) on current and cumulative production of $1 \mathrm{M}$ DRAMs for the six largest producers (Toshiba, Hitachi, Fujitsu, NEC, Mitsubishi, and Samsung), Flamm finds a steep (36 percent) learning

\footnotetext{
12 Nye (1989) avoids using price as a proxy for marginal cost by employing the Department of Commerce's "fair market value" cost measures developed for Japanese semiconductor firms in response to antidumping petitions filed in the mid-1980s. He finds a negative relationship between constructed cost and firm cumulative output for six firms. Beyond any reservations about the Commerce Department's methodology of constructing costs, the cost estimates are available only for a given point in time, allowing only cross-sectional estimates that cannot control for firm-specific cost effects.
} 
curve but insignificant coefficients on the inverse of firm-specific cumulative output.

There are several striking shortcomings of these few existing estimates of learning in the semiconductor industry: the limited and often outdated data sets employed, the failure to test whether spillovers exist, and the minimal efforts to control for other variables affecting price. To advance our understanding of learning by doing in this industry, we employ a richer data set and explore many of the hypotheses outlined in the previous section.

\section{Learning-by-Doing Spillovers in DRAM Production}

To distinguish between the hypotheses about the precise nature of learning by doing in the semiconductor industry, we use unpublished quarterly data from Dataquest on the average industry selling price and on shipments by each producing merchant firm (32 firms in all, with an average of 18 firms producing each type of chip) from 1974:1 to 1992:4 for each of seven successive generations of DRAMs: $4 \mathrm{~K}$, $16 \mathrm{~K}$ (and its 5-volt version), 64K, $256 \mathrm{~K}, 1 \mathrm{M}, 4 \mathrm{M}$, and $16 \mathrm{M} .{ }^{13}$ Figures 1 and 2 plot the average price and industry shipments in our sample period.

Strictly for comparison purposes, we begin by running simple aggregate regressions akin to those in the literature, where the log of the market price is regressed against the log of world cumulative output. The results from our sample may differ from those previously reported since we account for world output in a more comprehensive fashion and on a quarterly basis, and since additional generations of DRAMs are included. Table 1 presents results that show, as previous findings, that the $\bar{R}^{2}$ 's are typically above .90 and the learning coefficients are highly significant. These coefficients imply a learning rate that varies from 16 to 24 percent across generations, somewhat below the widely reported figure of 28 percent. In results we do not report, these findings are robust to the inclusion of a time dummy and to a first-difference specification.

\footnotetext{
${ }^{13}$ Dataquest is a private consulting firm located in San Jose, Calif., and is generally recognized as the leading source of reliable data on the semiconductor industry. For a detailed analysis of the Dataquest data, its quality, and collection methodology, see Flamm (1993b). We use shipment data because production data are unavailable. Inventories are reputed to be very small relative to shipments because, given the rapid product price declines, the holding costs of inventories are quite high. The sample excludes vertically integrated firms, such as IBM and Phillips, that produce DRAMs for internal consumption (captive markets) and not for sale on the open commodity market. See Appendix table Al for a list of all merchant and nonmerchant firms making arm's-length market transactions and therefore included in the sample.
} 


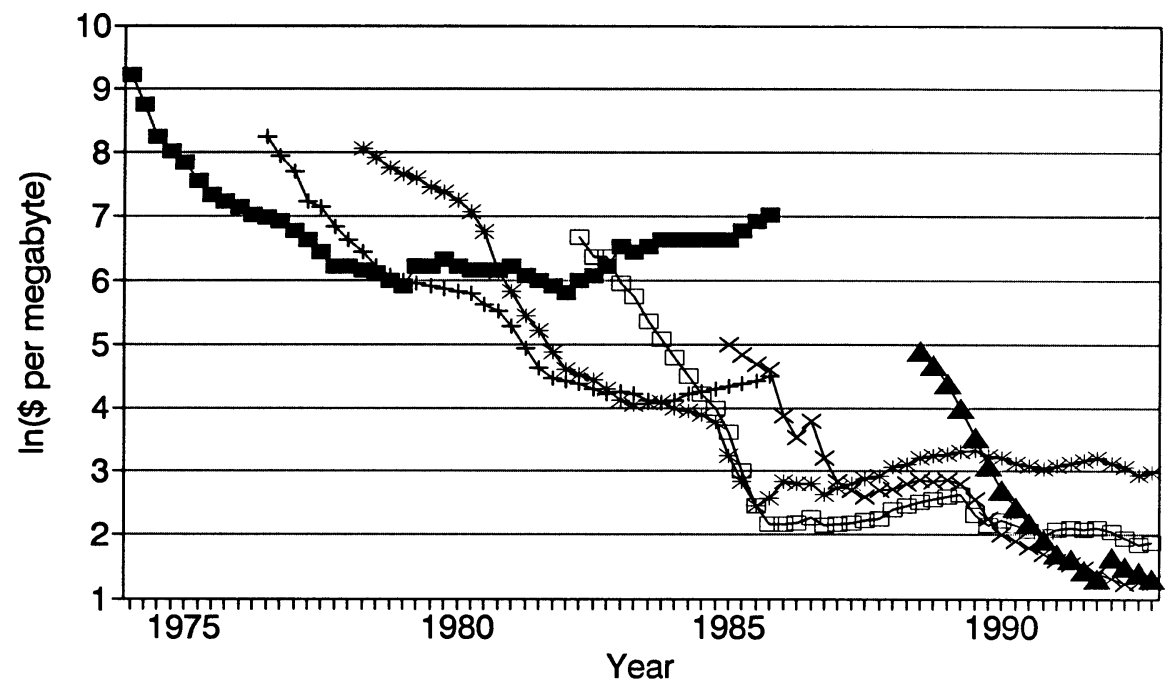

$$
\begin{aligned}
& \rightarrow-4 \mathrm{~K} \leftarrow 16 \mathrm{~K} \rightarrow 64 \mathrm{~K} \\
& \leftarrow 256 \mathrm{~K} \rightarrow 1 \mathrm{M} \rightarrow 4 \mathrm{M}
\end{aligned}
$$

FIG. 1.-DRAM prices (source: Dataquest)

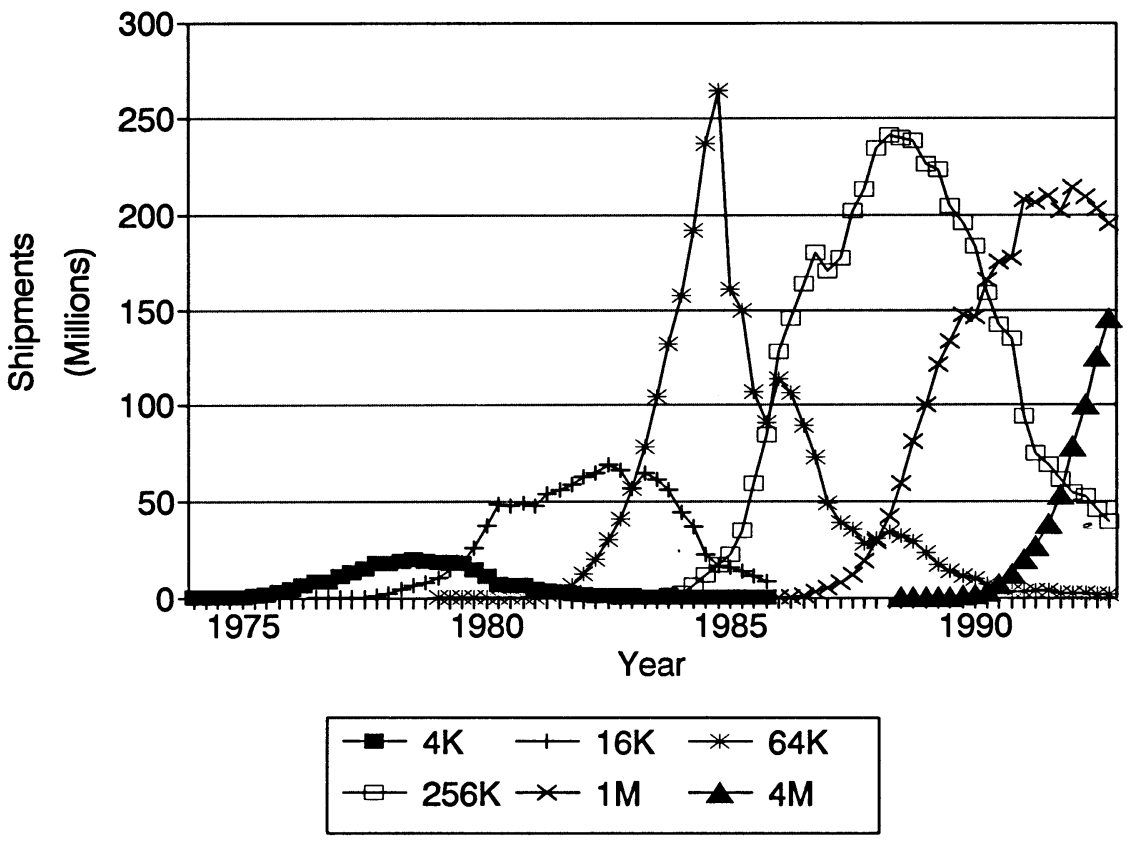

FIG. 2.-DRAM shipments (source: Dataquest) 
TABLE 1

“Aggregate" Learning by Doing

\begin{tabular}{|c|c|c|c|c|}
\hline & $\beta$ & $\bar{R}^{2}$ & Observations & $\begin{array}{c}\text { Learning } \\
\text { Rate } \\
(\%)\end{array}$ \\
\hline $4 \mathrm{~K}$ & $\begin{array}{c}-.329 \\
(.015)\end{array}$ & .91 & 47 & 20.4 \\
\hline $16 \mathrm{~K}$ & $\begin{array}{r}-.396 \\
(.020)\end{array}$ & .92 & 37 & 24.0 \\
\hline $16 \mathrm{~K}-5$ & $\begin{array}{c}-.291 \\
(.013)\end{array}$ & .95 & 26 & 18.3 \\
\hline $64 \mathrm{~K}$ & $\begin{array}{c}-.376 \\
(.009)\end{array}$ & .97 & 55 & 22.9 \\
\hline $256 \mathrm{~K}$ & $\begin{array}{r}-.332 \\
(.015)\end{array}$ & .93 & 40 & 20.6 \\
\hline $1 \mathrm{M}$ & $\begin{array}{r}-.260 \\
(.020)\end{array}$ & .86 & 29 & 16.5 \\
\hline $4 \mathrm{M}$ & $\begin{array}{r}-.325 \\
(.015)\end{array}$ & .97 & 17 & 20.2 \\
\hline $16 \mathrm{M}$ & $\begin{array}{c}-.251 \\
(.014)\end{array}$ & .98 & 6 & 16.0 \\
\hline
\end{tabular}

NoTE.-Standard errors are in parentheses. The learning rate is defined as $1-2^{\beta}$, i.e., the rate at which costs fall with each doubling of cumulative output.

\section{A. Estimation Approach}

Firm-level shipments data allow us to investigate a rich set of hypotheses about learning-by-doing spillovers, although the absence of plantlevel data precludes us from testing whether the benefits of learning are transferable across production facilities. In addition, we immediately confront the unavailability of any firm-level data on production costs. However, modeling the semiconductor firms as Cournot competitors producing a homogeneous good (in which the law of one market price holds, as is essentially the case in DRAMs) provides us with a theoretical structure in which cost data are not strictly required. Suppose that each firm $i$ chooses its output $y_{i}$ to maximize

$$
E_{0} \sum_{t=0}^{\infty}\left(\frac{1}{1+r}\right)^{t}\left[p\left(y_{t}\right) \cdot y_{i, t}-c_{i, t}(\cdot) \cdot y_{i, t}\right],
$$

where $E_{0}$ is the expectations operator conditional on information at time $0, r$ is a fixed discount rate, $p(\cdot)$ is the market inverse demand function, $y$ is industry output, and $c_{i}$ is firm $i$ 's marginal cost, the arguments of which will be described below. Then Cournot competition implies the following first-order condition relating price and marginal cost: 


$$
p \cdot\left(1+\frac{s_{i}}{\eta}\right)=c_{i}^{*}
$$

where $s_{i}$ is the market share of firm $i\left(y_{i} / y\right), \eta$ is the price elasticity of demand for semiconductors, and $c_{i}^{*}$ is the "dynamic" marginal cost of firm $i .^{14}$

The strictly positive markup in equation (2) does not contradict the notion that dynamic learning leads firms to price below current marginal cost in the early stages of production. As derived from (1), the marginal cost in equation (2) is dynamic in the presence of learning by doing, equaling static (current) marginal cost minus the reduction in future costs resulting from additional experience:

$$
p_{0}\left(1+\frac{s_{i, 0}}{\eta}\right)=c_{i, 0}+E_{0}\left[\sum_{t=1}^{\infty}\left(\frac{1}{1+r}\right)^{t} \cdot y_{i, t} \cdot \frac{\partial c_{i, t}(\cdot)}{\partial y_{i, 0}}\right]
$$

or, equivalently, in recursive form,

$$
\begin{aligned}
E_{t}\left\{p_{t}\left(1+\frac{s_{i, t}}{\eta}\right)-c_{i, t}-\frac{1}{1+r}[\right. & y_{i, t+1} \frac{\partial c_{i, t+1}}{\partial y_{i, t}} \\
& \left.\left.+p_{t+1} \cdot\left(1+\frac{s_{i, t+1}}{\eta}\right)-c_{i, t+1}\right]\right\}=0 .
\end{aligned}
$$

The first expression indicates that dynamic marginal cost takes into account the expected discounted value of future cost reductions due to the experience gained from current output. The second expression is the Euler equation, which is convenient for estimation. Hence, equation (2) is consistent with firms both pricing below current marginal cost and charging markups on the lower dynamic marginal cost.

Expression (2) implies that price-cost markups are higher for more efficient firms (those with lower marginal costs owing to greater learning experience, higher past $\mathrm{R} \& \mathrm{D}$, or favorable firm-specific fixed effects), which thereby enjoy larger market shares. The expression also implies-quite independently of learning effects-a declining price path over the product cycle: the first producer of a new generation enjoys a monopoly position and a large price-cost markup; as competitors begin production, that firm's market share and its markup decline.

Equation (2) holds only if firms are not capacity constrained. No clear consensus has emerged on whether capacity constraints com-

\footnotetext{
${ }^{14}$ Cournot competition abstracts from dynamic elements of competition, and we resort to it in lieu of a tractable alternative. It is not clear that this simplification biases our results on learning by doing or spillovers in any particular direction.
} 
monly bind in DRAM production. ${ }^{15}$ According to the Semiconductor Industry Association, capacity utilization in wafer fabrication has ranged from 43 to 78 percent over 1978-92 for all semiconductor products. If these capacity figures apply to DRAM production, then the assumption that capacity constraints do not bind seems appropriate.

In lieu of data on current marginal cost, our strategy is to infer it from the observables and equation (2). We observe market shares from our firm-level data, and the elasticity of demand for each generation of DRAM is taken as parametric. Estimates in the literature range from -1.5 to -2.3 , so we consider a baseline value of -1.8 and check for the robustness of the results to varying this value. ${ }^{16}$

We next assume that current marginal cost evolves with cumulative experience, $E_{i}$ (to be defined shortly):

$$
c_{i}=v_{i} \cdot E_{i}^{\beta} \cdot e^{u_{i}} .
$$

The error term $u_{i}$ represents technical change exogenous to the firm and is assumed to follow either

$$
u_{i, t}=\mu+\alpha \cdot t+\rho u_{i, t-1}+\varepsilon_{i, t}, \quad \text { with }|\rho|<1,
$$

or

$$
u_{i, t}=\mu+u_{i, t-1}+\varepsilon_{i, t}
$$

that is, we consider both trend stationary and difference stationary error terms in our estimation. Other than learning by doing and exogenous technical change, important influences on marginal cost include input prices (capital, labor, and materials) and $\mathrm{R} \& \mathrm{D}$ expenditures. We deal with the first factor by dividing the market price by the U.S. producer price index. Owing to lack of data, we cannot explicitly deal with $R \& D$ expenditures that increase productivity after a firm's DRAM production has commenced. We do deal with predetermined $R$ \& $D$ expenditures through firm-specific fixed effects $\left(v_{i}\right.$ in eq. [4]).

The crux of our investigation is to disentangle how firm, country, and world cumulative production contribute to the experience com-

${ }^{15}$ Fixed capacity is an integral component of Flamm's (1993a) simulation model of DRAM competition, although firms need not fully utilize all capacity. Indeed, Flamm is confident that capacity constraints were binding for DRAM producers only from 1988:3 to $1989: 2$.

${ }^{16}$ Several estimates of demand elasticities for semiconductors exist. Webbink (1977, p. 88) found a -1.6 value for dynamic integrated circuits in the early $1970 \mathrm{~s}$; Wilson, Ashton, and Egan (1980, p. 126) present a range from -1.8 to -2.3 ; Finan and Amundsen (1986, p. 321) use - 1.8; and Flamm (1993a, p. 69) computed - 1.5 for 1M DRAMs in the late 1980s. In their study of the 16K DRAM market, Baldwin and Krugman (1988) consider elasticities in the range of -1.4 to -2.2 . 
posite, $E_{i}$, in equation (4). We consider the following specification:

$$
E_{i}=Q_{i}+\alpha\left(Q_{C}-Q_{i}\right)+\gamma\left(Q_{W}-Q_{C}\right),
$$

where $Q_{i}$ is the cumulative output of firm $i, Q_{C}$ is the cumulative output of firm $i$ 's base country, and $Q_{W}$ is world cumulative output. Expression (4) nests several hypotheses, such as learning purely internal to the firm $(\alpha=\gamma=0)$, learning external to the firm but internal to the country $(\alpha=1, \gamma=0)$, and learning external to the firm and the country $(\alpha=1, \gamma=1)$. It also allows easy interpretation of alternative hypotheses, namely estimated parameter values in between the sharp hypothesized values. Values of $\alpha$ and $\gamma$ indicate the relative contribution of within- and between-country external production to experience. ${ }^{17}$

\section{B. Spillover Results}

Because equation ( $\left.3^{\prime}\right)$ includes unobserved expectations of future endogenous variables, instrumental variables estimation of equations $\left(3^{\prime}\right),(4)$, and (5) is necessary. We apply the generalized methods of moments with instruments including a time trend, seasonal dummies, lagged endogenous variables, exchange rates, and downstream demand in the form of computer output in the United States and Japan. As the results in table 2 indicate, this procedure yielded precise estimates of the learning parameter but imprecise estimates of the spillover parameters. The learning rate varies from 10 to 27 percent, averaging 20 percent across the eight generations. ${ }^{18}$ Although the standard errors on the spillover parameters are large, the spillover coefficients are (with one exception) considerably below unity, implying largely internal learning, and within-country spillovers appear no stronger than international spillovers.

${ }^{17}$ The additive specification of (4) posits an infinite elasticity of substitution between firm and extra-firm cumulative production in their contribution to learning. Simply put, different sources of production push each firm down a single learning curve. Two alternative specifications, the first of which nests the several hypotheses of interest, are $E_{i}=Q_{i}^{\alpha_{1}} Q_{C}^{\alpha_{2}} Q_{W}^{\alpha_{3}}$ and $E_{i}=Q_{i}^{\alpha_{1}}\left(Q_{C}-Q_{i}\right)^{\alpha_{2}}\left(Q_{W}-Q_{C}\right)^{\alpha_{3}}$. These specifications imply unit elasticity of substitution between the different sources of cumulative output in their contribution to experience; i.e., they imply three separate learning curves, one for each source of cumulative production. This does not allow for easy interpretation of parameter values away from the sharp hypothesized values. Still, for comparison purposes we repeated the estimation with the alternative specifications and found identical outcomes for each of the sharp hypothesis tests.

${ }^{18}$ These learning rates are comparable to those obtained simply from regressing price on cumulative industry output. We might have expected slower learning rates with our specification, given that ours attributes some of the price decline to falling markups rather than learning. However, the table 1 estimates assume only world learning, thereby overstating the experience variable and understating the learning rate. 
TABLE 2

Learning-by-Doing Spillovers: Generalized Method of Moments Estimates

\begin{tabular}{lcccccc}
\hline \hline & $\beta$ & $\alpha$ & $\gamma$ & $J$-Statistic & Observations & $\begin{array}{c}\text { Learning } \\
\text { Rate }\end{array}$ \\
\hline $4 \mathrm{~K}$ & -.348 & .286 & .248 & 81.3 & 372 & 21.4 \\
& $(.081)$ & $(.286)$ & $(.691)$ & & & \\
$16 \mathrm{~K}$ & -.456 & .363 & .388 & 162.7 & 476 & 27.1 \\
& $(.023)$ & $(.167)$ & $(.181)$ & & & \\
$16 \mathrm{~K}-5$ & -.233 & .042 & .365 & 43.9 & 113 & 14.9 \\
& $(.098)$ & $(.142)$ & $(.609)$ & & & \\
$64 \mathrm{~K}$ & -.375 & .483 & .487 & 107.4 & 614 & 22.9 \\
& $(.032)$ & $(.669)$ & $(.411)$ & & & \\
$256 \mathrm{~K}$ & -.318 & 2.270 & 2.002 & 213.6 & 579 & 19.8 \\
& $(.236)$ & $(3.172)$ & $(2.616)$ & & & \\
$1 \mathrm{M}$ & -.269 & .215 & .810 & 103.6 & 379 & 17.0 \\
& $(.087)$ & $(.699)$ & $(1.102)$ & & & \\
$4 \mathrm{M}$ & -.428 & .516 & .682 & 105.0 & 180 & 25.7 \\
$16 \mathrm{M}$ & $(.095)$ & $(.094)$ & $(.337)$ & & & 10.3 \\
& -.157 & .250 & .327 & 8.1 & 38 & \\
\hline
\end{tabular}

Note.-See table 1. Definitions: $\alpha$ is within-country spillovers and $\gamma$ is cross-country spillovers. The $J$-statistic equals $N \cdot$ (GMM minimand) and is distributed $\chi^{2}$ with seven degrees of freedom.

In search of more precise estimates of the spillover parameters, we assume that dynamic marginal cost (rather than current marginal cost) evolves with experience. Therefore, we replace equation (4) with

$$
c_{i}^{*}=v \cdot E_{i}^{\beta} \cdot e^{u_{i}} .
$$

The advantage of (6) is that instruments are no longer necessary. We employ nonlinear least squares to estimate equations (3), (5), and (6) and present our results in table 3 . The learning rates are comparable to those found in previous tables. Using likelihood ratio tests, we can reject (at critical values below 1 percent) the hypotheses of purely internal learning $(\alpha=\gamma=0)$ and learning external to the firm but internal to the country $(\alpha=1, \gamma=0)$ for each of the eight cases. We can reject the hypothesis of world learning in six out of eight cases; the remaining two have $p$-values of 14 and 2 percent, providing weak support for the null. ${ }^{19}$

Having found evidence against spillovers solely within each coun-

19 If eq. (4) is the true model, estimates using (6) should bias downward the learning speed estimates and bias upward the spillover estimates since dynamic marginal cost falls less quickly with experience. Dynamic marginal cost falls less quickly than current marginal cost for two distinct reasons: First, specification (4) implies diminishing marginal learning from additional output as experience rises; i.e. firms learn less and less from successive units of output. Second, the future interval over which current production yields experience benefits is finite and shrinking as the uncertain terminal production date approaches. 
TABLE 3

Learning-by-Doing Spillovers: Nonlinear Least Squares Estimates

\begin{tabular}{|c|c|c|c|c|c|c|c|}
\hline & $\beta$ & $\alpha$ & $\gamma$ & $\bar{R}^{2}$ & Observations & $(\alpha-\gamma)^{*}$ & $\begin{array}{c}\text { Learning } \\
\text { Rate }\end{array}$ \\
\hline $4 \mathrm{~K}$ & $\begin{array}{r}-.350 \\
(.006)\end{array}$ & $\begin{array}{l}.300 \\
(.048)\end{array}$ & $\begin{array}{c}.310 \\
(.047)\end{array}$ & .90 & 374 & .037 & 21.5 \\
\hline $16 \mathrm{~K}$ & $\begin{array}{r}-.488 \\
(.008)\end{array}$ & $\begin{array}{l}.176 \\
(.038)\end{array}$ & $\begin{array}{l}.238 \\
(.039)\end{array}$ & .90 & 489 & .002 & 28.7 \\
\hline $16 \mathrm{~K}-5$ & $\begin{array}{c}-.217 \\
(.009)\end{array}$ & $\begin{array}{l}.263 \\
(.074)\end{array}$ & $\begin{array}{c}.241 \\
(.096)\end{array}$ & .85 & 118 & .201 & 14.0 \\
\hline $64 \mathrm{~K}$ & $\begin{array}{c}-.375 \\
(.005)\end{array}$ & $\begin{array}{l}.335 \\
(.096)\end{array}$ & $\begin{array}{l}.425 \\
(.105)\end{array}$ & .91 & 623 & .036 & 22.9 \\
\hline $256 \mathrm{~K}$ & $\begin{array}{c}-.314 \\
(.006)\end{array}$ & $\begin{array}{l}.328 \\
(.105)\end{array}$ & $\begin{array}{c}.369 \\
(.099)\end{array}$ & .82 & 593 & .044 & 19.6 \\
\hline $1 \mathrm{M}$ & $\begin{array}{c}-.293 \\
(.009)\end{array}$ & $\begin{array}{l}.130 \\
(.048)\end{array}$ & $\begin{array}{c}.247 \\
(.072)\end{array}$ & .76 & 399 & -.033 & 18.4 \\
\hline $4 \mathrm{M}$ & $\begin{array}{c}-.299 \\
(.006)\end{array}$ & $\begin{array}{l}.450 \\
(.152)\end{array}$ & $\begin{array}{l}.465 \\
(.145)\end{array}$ & .93 & 199 & .102 & 18.7 \\
\hline $16 \mathrm{M}$ & $\begin{array}{c}-.251 \\
(.006)\end{array}$ & $\begin{array}{l}.233 \\
(.041)\end{array}$ & $\begin{array}{l}.274 \\
(.042)\end{array}$ & .98 & 47 & .010 & 16.0 \\
\hline
\end{tabular}

Note.-See table 2.

* The largest value of $(\alpha-\gamma)$ that, as a null hypothesis, cannot be rejected at the 5 percent level.

try, one still might maintain that within-country spillovers are stronger than between-country spillovers. We test the null hypothesis $H_{0}: \alpha-\gamma=\delta>0$ by calculating the largest value of $\alpha-\gamma$ that cannot be rejected at 5 percent; that is, larger values of $\alpha-\gamma$ can be rejected at the 5 percent level, smaller values cannot. As reported in table 3 , we find in six of the eight cases that only small values of $\alpha-\gamma$ are defensible null hypotheses. In the other two cases, the data do not reject significantly larger domestic than international spillovers. In these two cases, however, the data are simply not informative: we also cannot reject the hypothesis (even at 80 percent significance) that $\alpha=\gamma$, that is, that learning spills over just as much between firms in different countries as between firms within a given country. ${ }^{20}$

The respective estimates of $\alpha$ and $\gamma$ average .28 and .32 over the various DRAM generations. This implies that a firm learns over three times as much from an additional unit of its own cumulative output as from an additional unit of another firm's cumulative output, regardless of the other firm's country of location. However, rest-ofworld cumulative production is typically more than three times any

\footnotetext{
${ }^{20}$ The hypothesis that $\alpha=\gamma$ cannot be rejected in four of the other six cases at the 10 percent significance level. In the remaining two, this hypothesis is rejected but $\hat{\alpha}<\hat{\gamma}$.
} 
given firm's cumulative production. This means that the absolute contribution of world cumulative production to each firm's experience outweighs the absolute contribution of its own cumulative production. In this sense, spillovers are substantial. Yet, in terms of the marginal incentives of the firm, most of the learning is internalized.

This distinction bears crucially on the degree to which firms underproduce relative to the social optimum and therefore on the need for policy intervention. The finding of important firm-specific learning indicates that firms have an incentive to capture learning benefits. The finding of a spillover, meanwhile, does not provide support for policies favoring domestic over foreign firms, given that the spillovers are international. Any country that subsidizes its domestic firms in part provides an international public good.

Indeed, the policy implications of our findings are not at all clear. The spillover coefficients may not represent an external economy, but instead market (joint ventures or labor mobility) or nonmarket (quid pro quo communication among engineers) exchanges between firms. The results are not informative about the transmission mechanism of spillovers, and as a result, direct policy conclusions do not follow. We obtained data on joint production ventures between DRAM producers over the last five generations to explore whether spillovers merely reflect shared knowledge between venture partners. The results, which we do not report, were not precise enough to determine whether spillovers were stronger among joint venture partners compared with unaligned firms. Learning appears to spill over just as much between nonaligned firms as between firms within a joint venture.

Stokey (1986) emphasizes a tension between market concentration and industrywide learning that suggests further caution about drawing policy conclusions from our results. Since much learning appears to be internal to the firm, firms face dynamic increasing returns to scale that promote market concentration. Market concentration in turn implies greater internalization of industrywide learning by each firm, raising output toward the social optimum. Yet such concentration potentially increases market power, inducing firms to restrict output away from the social optimum. Depending on how these tensions are resolved, the deviation of output from the social optimum in the presence of industrywide learning may be larger or smaller than under perfect competition. Without detailed information on industry structure, one cannot accurately determine optimal policies regarding output and entry/exit promotion.

Before addressing other issues, we check to see whether the results in table 3 are robust. Table 4 presents results that include a time trend $(\mu)$ and broadly support the conclusions of table 3 : the learning 
TABLE 4

Learning-by-Doing Spillovers: Nonlinear Least SQuares Estimates

\begin{tabular}{lccccccc}
\hline \hline & $\beta$ & $\alpha$ & $\gamma$ & $\mu$ & $\bar{R}^{2}$ & Observations & $\begin{array}{c}\text { Learning } \\
\text { Rate }\end{array}$ \\
\hline $4 \mathrm{~K}$ & -.359 & .298 & .308 & .002 & .90 & 374 & 22.0 \\
& $(.010)$ & $(.047)$ & $(.045)$ & $(.002)$ & & & \\
$16 \mathrm{~K}$ & -.324 & .227 & .280 & -.039 & .92 & 489 & 20.1 \\
& $(.016)$ & $(.066)$ & $(.067)$ & $(.003)$ & & & \\
$16 \mathrm{~K}-5$ & -.295 & .293 & .282 & .024 & .86 & 118 & 18.5 \\
& $(.027)$ & $(.060)$ & $(.079)$ & $(.008)$ & & & \\
$64 \mathrm{~K}$ & -.359 & .382 & .459 & -.004 & .91 & 623 & 22.1 \\
& $(.008)$ & $(.119)$ & $(.125)$ & $(.002)$ & & & \\
$256 \mathrm{~K}$ & -.346 & .312 & .355 & .008 & .82 & 563 & 21.3 \\
& $(.012)$ & $(.089)$ & $(.084)$ & $(.002)$ & & & \\
$1 \mathrm{M}$ & -.018 & .000 & .000 & -.093 & .92 & 399 & 1.3 \\
& $(.014)$ & $(.000)$ & $(.000)$ & $(.005)$ & & & \\
$4 \mathrm{M}$ & -.545 & .417 & .458 & .155 & .97 & 199 & 31.5 \\
& $(.016)$ & $(.050)$ & $(.050)$ & $(.010)$ & & & \\
$16 \mathrm{M}$ & -.099 & .062 & .096 & -.135 & .99 & 47 & 6.7 \\
& $(.024)$ & $(.037)$ & $(.039)$ & $(.021)$ & & & \\
\hline
\end{tabular}

Note.-See table 2. $\mu$ is a time trend.

rate averages 18 percent, spillovers are slightly below .3 on average, and within-country spillovers are no stronger than between-country spillovers. The time trend significantly affects only the results for the $1 \mathrm{M}$ and $16 \mathrm{M}$ generations. In results we do not report, our conclusions from table 3 are also unchanged with the adoption of a firstdifference specification, which implicitly removes any firm fixed effects. Another potentially important bias arises from sample selection: firms with "good" unobservables are more likely to be included in the sample and those with "bad" unobservables excluded. This creates a negative correlation in the sample between the disturbance and the experience variable. To gauge whether this bias is sizable, we construct a balanced subsample consisting of continuously producing firms. In results we do not report, these restricted samples produce nearly identical results to those in table 3 .

Our results are sensitive in a minor but reasonable way to variations in the demand elasticity. With a demand elasticity of -1.4 instead of -1.8 , average learning slows marginally (from 20.0 to 19.6) and spillovers are weaker (within- and between-country spillovers averaging .19 and .23, respectively); with a demand elasticity of -2.2 , average learning increases marginally (to 20.1) and spillovers are slightly stronger (.35 and .40$)$. These findings are intuitive: the more steeply sloped the demand curve, the less learning and spillovers are required to explain the sharp declines in price. 


\section{Is Japan Different?}

Table 5 addresses the issue of whether Japanese firms learn more from production experience (i.e., enjoy a steeper learning curve) than firms elsewhere. Here we allow the learning parameter to differ for Japan-based firms relative to that for all other firms. Consider the null hypothesis that Japanese firms learn more from production experience than other firms do, that is, $H_{0}: \beta_{J}>\beta$. As shown in table 5 , only trivially small values of $\beta_{J}-\beta$ cannot be rejected at the 5 percent level, leaving tenuous support for the null hypothesis. Not surprisingly then, for seven out of eight generations we cannot reject the hypothesis that the two learning coefficients are equal $\left(\beta_{J}=\beta\right)$ at conventional significance levels. ${ }^{21}$ There appears to be no empirical basis for believing that Japanese firms are systematically better at learning from production experience than other firms. Whereas table 5 addresses the slope of the learning curve, another hypothesis is that the intercept or starting point of the learning curve is lower for Japanese firms; that is, there is a fixed effect for Japan. In results we do not report, we find no evidence of lower Japanese firm costs.

Table 6 addresses whether Japanese firms learn more from each other than firms in other countries learn from each other, that is, whether $\alpha_{J}>\alpha$. In five out of seven cases, the data cannot reject much stronger learning spillovers in Japan than within other countries. ${ }^{22}$ However, the data also cannot reject the null hypothesis that $\alpha_{J}=\alpha$ in six of seven cases. ${ }^{23}$ Consequently, unlike our results on Japanese learning speeds, our results on spillovers in Japan are unable to discriminate between competing hypotheses.

We test two additional hypotheses about how spillovers might differ for Japanese firms, results for which we do not report in tables. First, is there "one-way learning" in that Japanese firms learn from firms in other countries but not vice versa? We can reject this hypothesis for six of eight DRAM generations, and we cannot reject the hypothesis of symmetric two-way learning in all eight cases. Second, at the other extreme, do Japanese firms "stick to themselves," learning neither from each other nor from firms in other countries? In all eight cases we can reject this hypothesis at the 1 percent level.

We also examine the effects of the 1986 Semiconductor Trade Arrangement between the United States and Japan, an agreement that compelled the Japanese government to encourage firms in Japan

${ }^{21}$ For 1 M DRAMs, we reject the hypothesis of equal learning rates at the critical value of 1 percent. The point estimates imply a 17.7 percent learning rate for Japanese firms and a 16.7 percent learning rate for other firms.

${ }^{22}$ The limited number of non-Japanese firms producing 16M DRAMs precludes us from testing this proposition for this last generation.

${ }^{23}$ In $1 \mathrm{M}$, we can reject symmetry, but in this case $\hat{\alpha}>\hat{\alpha}_{J}$. 


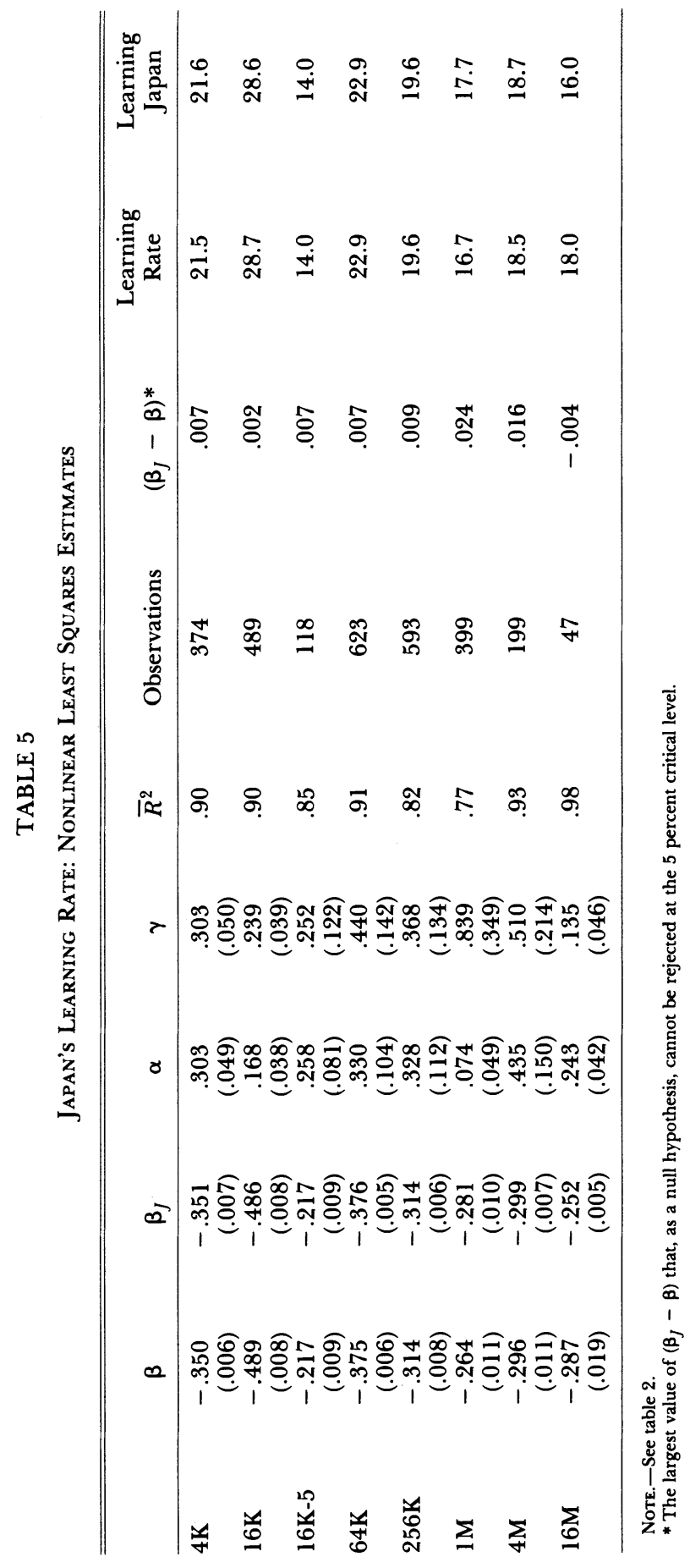


TABLE 6

Japan's Spillovers: Nonlinear Least SQuares Estimates

\begin{tabular}{|c|c|c|c|c|c|c|c|}
\hline & $\beta$ & $\alpha$ & $\alpha_{J}$ & $\gamma$ & $\bar{R}^{2}$ & Observations & $\left(\alpha_{J}-\alpha\right)^{*}$ \\
\hline $4 K$ & $\begin{array}{c}-.350 \\
(.006)\end{array}$ & $\begin{array}{l}.300 \\
(.048)\end{array}$ & $\begin{array}{c}.410 \\
(.326)\end{array}$ & $\begin{array}{l}.303 \\
(.050)\end{array}$ & .90 & 374 & .638 \\
\hline $16 \mathrm{~K}$ & $\begin{array}{c}-.488 \\
(.008)\end{array}$ & $\begin{array}{l}.176 \\
(.038)\end{array}$ & $\begin{array}{l}.115 \\
(.060)\end{array}$ & $\begin{array}{l}.248 \\
(.042)\end{array}$ & .90 & 489 & .022 \\
\hline $16 \mathrm{~K}-5$ & $\begin{array}{r}-.216 \\
(.009)\end{array}$ & $\begin{array}{l}.277 \\
(.075)\end{array}$ & $\begin{array}{l}.541 \\
(.335)\end{array}$ & $\begin{array}{l}.167 \\
(.088)\end{array}$ & .85 & 118 & .780 \\
\hline $64 \mathrm{~K}$ & $\begin{array}{c}-.375 \\
(.005)\end{array}$ & $\begin{array}{l}.160 \\
(.129)\end{array}$ & $\begin{array}{l}.365 \\
(.113)\end{array}$ & $\begin{array}{l}.533 \\
(.156)\end{array}$ & .91 & 623 & .424 \\
\hline $256 \mathrm{~K}$ & $\begin{array}{c}-.314 \\
(.006)\end{array}$ & $\begin{array}{l}.171 \\
(.259)\end{array}$ & $\begin{array}{l}.328 \\
(.106)\end{array}$ & $\begin{array}{l}.391 \\
(.113)\end{array}$ & .82 & 593 & .579 \\
\hline $1 \mathrm{M}$ & $\begin{array}{c}-.293 \\
(.008)\end{array}$ & $\begin{array}{l}1.134 \\
(.375)\end{array}$ & $\begin{array}{l}.139 \\
(.044)\end{array}$ & $\begin{array}{l}.107 \\
(.039)\end{array}$ & .77 & 399 & -.414 \\
\hline $4 \mathrm{M}$ & $\begin{array}{c}-.300 \\
(.006)\end{array}$ & $\begin{array}{c}-.004 \\
(.600)\end{array}$ & $\begin{array}{l}.443 \\
(.148)\end{array}$ & $\begin{array}{l}.480 \\
(.149)\end{array}$ & .94 & 199 & 1.442 \\
\hline
\end{tabular}

Note.-See table 2.

* The largest value of $\left(\alpha_{J}-\alpha\right)$ that, as a null hypothesis, cannot be rejected at the 5 percent level.

to reduce output, as discussed in Irwin (1995). Three generations of DRAMs straddle the 1986 accord and allow us to identify its impact. A dummy variable on all Japanese production beginning in 1987:3 (after the United States had retaliated for Japan's noncompliance with the agreement) brings highly significant coefficients for the $64 \mathrm{~K}$, $256 \mathrm{~K}$, and $1 \mathrm{M}$ generations (.23 with a standard error of $.06, .26$ with a standard error of .04 , and .06 with a standard error of .03 , respectively). Loosely speaking, the agreement was equivalent in its impact to about a 25 percent increase in Japanese producer costs for $64 \mathrm{~K}$ and $256 \mathrm{~K}$ DRAMs. The striking results illustrate the effect of mid-product cycle production cutbacks in Japan for $64 \mathrm{~K}$ and $256 \mathrm{~K}$ DRAMs. The impact on 1M DRAMs, which were just beginning production, is less discernible.

\section{Intergenerational Spillovers}

Table 7 addresses the issue of intergenerational spillovers. Here we modify the experience composite as follows:

$$
E_{i}=\left[Q_{i}+\omega\left(Q_{W}-Q_{i}\right)\right]+\Psi\left[\tilde{Q}_{i}+\omega\left(\tilde{Q}_{W}-\tilde{Q}_{i}\right)\right],
$$

where the variables with tildes denote the previous DRAM generation. This allows us to test the proposition that, for example, production experience in $64 \mathrm{~K}$ DRAMs benefits a firm in the production of 256K DRAMs. This specification imposes $\alpha=\gamma$ (a hypothesis that could not be rejected earlier) to obtain more precise estimates. We 
TABLE 7

INTERGENERATIONAL LEARNING-BY-DOING SPILlOVERS:

Nonlinear Least Squares Estimates

\begin{tabular}{lccccc}
\hline \hline & $\beta$ & $\alpha, \gamma$ & $\Psi$ & $\bar{R}^{2}$ & Observations \\
\hline $16 \mathrm{~K}$ & -.848 & .655 & .362 & .95 & 489 \\
& $(.056)$ & $(.094)$ & $(.098)$ & & \\
$16 \mathrm{~K}-5$ & -.206 & .213 & -.0006 & .86 & 118 \\
& $(.009)$ & $(.052)$ & $(.0002)$ & & \\
$64 \mathrm{~K}$ & -.395 & .345 & .313 & .91 & 623 \\
& $(.010)$ & $(.081)$ & $(.195)$ & & \\
$256 \mathrm{~K}$ & -.314 & .368 & .000 & .82 & 593 \\
& $(.007)$ & $(.107)$ & $(.0001)$ & & \\
$1 \mathrm{M}$ & -.619 & .332 & .128 & .87 & 399 \\
& $(.069)$ & $(.062)$ & $(.061)$ & & \\
$4 \mathrm{M}$ & -.293 & .416 & .000 & .94 & 199 \\
& $(.007)$ & $(.126)$ & $(.000)$ & & \\
$16 \mathrm{M}$ & -.303 & .287 & .000 & .99 & 47 \\
& $(.013)$ & $(.035)$ & $(.000)$ & & \\
\hline
\end{tabular}

NotE.-See table 2. $\Psi$ is intergenerational spillovers.

implicitly assume that only experience in the previous generation lowers costs in the current generation; thus knowledge depreciates fully after two generations. For example, production experience with $4 \mathrm{~K}$ may help with $16 \mathrm{~K}$ production but is not applicable to subsequent generations. Given the considerable overlap of production of adjacent DRAM generations, production experience in the previous generation does not represent a firm fixed effect during production of the new generation.

The results shown in table 7 indicate that $\hat{\Psi}$ is statistically significant in five of seven cases but economically significant in only two cases: $4 \mathrm{~K}$ experience applies to $16 \mathrm{~K}$ production and $256 \mathrm{~K}$ experience applies to $1 \mathrm{M}$ production. ${ }^{24}$ The intergenerational spillover of $4 \mathrm{~K}$ production knowledge onto $16 \mathrm{~K}$ was mentioned frequently in the debate over Japanese entry into DRAM production in the late 1970s. The absence of spillovers from $16 \mathrm{~K}$ experience to $64 \mathrm{~K}$ production is consistent with the successful entry of seven new firms in the DRAM market, despite their lack of production experience, concurrent with the exit

${ }^{24}$ The three other cases are $16 \mathrm{~K}-5$ learning from $16 \mathrm{~K}$, $4 \mathrm{M}$ learning from $1 \mathrm{M}$, and $16 \mathrm{M}$ from $4 \mathrm{M}$. These results are economically insignificant in that $\Psi$ is so small (even when multiplied by the final cumulative production in the previous generation) that experience in the previous generation contributes trivially to production experience in the current generation. Put differently, the learning from initial production in a new generation dwarfs the contribution arising from the previous generation's output. 
of five firms. A similar phenomenon occurs between $64 \mathrm{~K}$ and $256 \mathrm{~K}$ production, with four firms entering and three firms exiting. The estimated $\Psi$ for $64 \mathrm{~K}$ chips is large and positive but not significant, and is zero for $256 \mathrm{~K}$. For $4 \mathrm{M}$ and $16 \mathrm{M}$, the most recent generations in our sample, there appear to be no intergenerational spillovers. ${ }^{25}$

In sum, intergenerational spillovers occur in only two of seven DRAM generations. This appears to undercut concerns that Japanese industrial targeting permanently affects production and trade in semiconductors. The absence of important intergenerational spillovers also diminishes the potential advantage of industrial policies designed to promote the semiconductor industry because, given the rapid product cycles in the industry, any gains from such policies are likely to be extremely short-lived.

\section{Conclusions}

This paper provides the first systematic empirical evidence on learning-by-doing spillovers within the semiconductor industry. To summarize, we find that $(a)$ learning rates average 20 percent, $(b)$ firms learn three times more from an additional unit of their own cumulative production than from an additional unit of another firm's cumulative production, $(c)$ learning spills over just as much between firms in different countries as between firms within a given country, $(d)$ Japanese firms are indistinguishable from others in learning speeds, and $(e)$ intergenerational spillovers are weak, being marginally significant in only two of seven DRAM generations.

Our results lend insight into the specific nature of spillovers in this industry and therefore clarify appropriate trade and industrial policies toward the industry, as well as shed light on the role of learning in economic growth. We are led to three broad conclusions. First, the significant learning rates we find strengthen the case that learning contributes to economic growth, but the absence of strong support for intergenerational learning spillovers weakens the case. Second, the evidence we find for learning-by-doing spillovers indicates that the spillovers are international in scope and therefore provide no clear justification for policies that favor domestic over foreign firms. Third, the lack of important intergenerational spillovers, combined with short (3-5 year) product cycles, implies that any gains from promoting the industry may be short-lived.

${ }^{25}$ The estimates of intergenerational spillovers are potentially biased by sample selection. Balanced samples of firms that produce in the current and previous generations yield virtually identical results. 


\section{Appendix}

TABLE Al

Merchant DRAM Producers, 1974-92

\begin{tabular}{|c|c|c|c|c|c|c|c|c|}
\hline Firm & Country & $4 \mathrm{~K}$ & $16 \mathrm{~K}$ & $64 \mathrm{~K}$ & $256 \mathrm{~K}$ & $1 \mathrm{M}$ & $4 \mathrm{M}$ & $16 \mathrm{M}$ \\
\hline AMD & United States & $\mathbf{x}$ & $\mathbf{x}$ & $\mathbf{x}$ & & & & \\
\hline AMI & United States & $\mathbf{x}$ & & & & & & \\
\hline AT\&T-Tech & United States & & & & $\mathbf{x}$ & $\mathbf{x}$ & & \\
\hline Eurotechnique & Europe & & $\mathrm{x}$ & & & & & \\
\hline Fairchild & United States & $\mathbf{x}$ & $\mathbf{x}$ & $\mathbf{x}$ & & & & \\
\hline Fujitsu & Japan & $\mathbf{x}$ & $\mathbf{x}$ & $\mathbf{x}$ & $\mathbf{x}$ & $\mathbf{x}$ & $\mathbf{x}$ & $\mathbf{x}$ \\
\hline Goldstar & South Korea & & & & $\mathbf{x}$ & $\mathbf{x}$ & $\mathbf{x}$ & \\
\hline Hitachi & Japan & $\mathbf{x}$ & $\mathbf{x}$ & $\mathbf{x}$ & $\mathbf{x}$ & $\mathbf{x}$ & $\mathbf{x}$ & $\mathbf{x}$ \\
\hline Hyundai & South Korea & & & $\mathbf{x}$ & $\mathbf{x}$ & $\mathbf{x}$ & $\mathbf{x}$ & \\
\hline Ińmos & United States & & & $\mathbf{x}$ & $\mathbf{x}$ & & & \\
\hline Intel & United States & $\mathbf{x}$. & $\mathbf{x}$ & $\mathbf{x}$ & $\mathbf{x}$ & $\mathbf{x}$ & & \\
\hline Intersil & United States & $\mathbf{x}$ & $\mathbf{x}$ & & & & & \\
\hline Matsushita & Japan & & $\mathbf{x}$ & $\mathbf{x}$ & $\mathbf{x}$ & $\mathbf{x}$ & $\mathbf{x}$ & $\mathbf{x}$ \\
\hline Micron & United States & & & $\mathbf{x}$ & $\mathbf{x}$ & $\mathbf{x}$ & $\mathbf{x}$ & \\
\hline Mitsubishi & Japan & & $\mathbf{x}$ & $\mathbf{x}$ & $\mathbf{x}$ & $\mathbf{x}$ & $\mathrm{x}$ & $\mathbf{x}$ \\
\hline Mostek & United States & $\mathbf{x}$ & $\mathbf{x}$ & $\mathbf{x}$ & $\mathbf{x}$ & & $\mathbf{x}$ & \\
\hline Motorola & United States & $\mathbf{x}$. & $\mathbf{x}$ & $\mathbf{x}$ & $\mathbf{x}$ & $\mathbf{x}$ & $\mathbf{x}$ & \\
\hline National & United States & $\mathbf{x}$ & $\mathbf{x}$ & $\mathbf{x}$ & $\mathbf{x}$ & & & \\
\hline NEC & Japan & $\mathbf{x}$ & $\mathbf{x}$ & $\mathbf{x}$ & $\mathbf{x}$ & $\mathbf{x}$ & $\mathbf{x}$ & $\mathbf{x}$ \\
\hline NMB & Japan & & & & $\mathbf{x}$ & $\mathbf{x}$ & $\mathbf{x}$ & \\
\hline Oki & Japan & & & $\mathbf{x}$ & $\mathbf{x}$ & $\mathbf{x}$ & $\mathbf{x}$ & $\mathbf{x}$ \\
\hline Samsung & South Korea & & & $\mathbf{x}$ & $\mathbf{x}$ & $\mathbf{x}$ & $\mathbf{x}$ & $\mathbf{x}$ \\
\hline Sanyo & Japan & & & & $\mathbf{x}$ & $\mathbf{x}$ & $\mathbf{x}$ & \\
\hline SGS-Ates & Europe & $\mathbf{x}$ & $\mathbf{x}$ & & & & & \\
\hline Sharp & Japan & & & $\mathbf{x}$ & $\mathbf{x}$ & $\mathbf{x}$ & $\mathbf{x}$ & \\
\hline Siemens & Europe & & $\mathbf{x}$ & $\mathbf{x}$ & $\mathbf{x}$ & $\mathbf{x}$ & $\mathbf{x}$ & \\
\hline Signetics & United States & $\mathbf{x}$ & $\mathbf{x}$ & & & & & \\
\hline STC (ITT) & United States & $\mathbf{x}$ & $\mathbf{x}$ & $\mathbf{x}$ & & & & \\
\hline Texas Instruments & United States & $\mathbf{x}$ & $\mathbf{x}$ & $\mathbf{x}$ & $\mathbf{x}$ & $\mathbf{x}$ & $\mathbf{x}$ & $\mathbf{x}$ \\
\hline Toshiba & Japan & & $\mathbf{x}$ & $\mathbf{x}$ & $\mathbf{x}$ & $\mathbf{x}$ & $\mathbf{x}$ & $\mathbf{x}$ \\
\hline Vitelic & United States & & & $\mathbf{x}$ & $\mathbf{x}$ & $\mathbf{x}$ & & \\
\hline Zilog & United States & & $\mathbf{x}$ & & & & & \\
\hline
\end{tabular}

\section{References}

Aghion, Philippe, and Howitt, Peter. "A Model of Growth through Creative Destruction." Econometrica 60 (March 1992): 323-51.

Alchian, Armen A. "Reliability of Progress Curves in Airframe Production." Econometrica 31 (October 1963): 679-93.

Arrow, Kenneth J. "The Economic Implications of Learning by Doing." Rev. Econ. Studies 29 (June 1962): 155-73.

Baldwin, Richard E., and Krugman, Paul R. "Market Access and International Competition: A Simulation Study of 16K Random Access Memories." In Empirical Methods for International Trade, edited by Robert C. Feenstra. Cambridge, Mass.: MIT Press, 1988.

Borrus, Michael; Millstein, James; and Zysman, John. U.S.-Japanese Competition in the Semiconductor Industry. Policy Papers in International Affairs, no. 17. Berkeley: Univ. California, Inst. Internat. Studies, 1982. 
Borrus, Michael; Tyson, Laura D’Andrea; and Zysman, John. "Creating Advantage: How Government Policies Shape International Trade in the Semiconductor Industry." In Strategic Trade Policy and the New International Economics, edited by Paul R. Krugman. Cambridge, Mass.: MIT Press, 1986.

$\rightarrow$ Dick, Andrew R. "Learning by Doing and Dumping in the Semiconductor Industry." J. Law and Econ. 34 (April 1991): 133-59.

Federal Interagency Staff Working Group. The Semiconductor Industry. Washington: Government Printing Office, November 16, 1987.

$\rightarrow$ Finan, William F., and Amundsen, Chris B. "Modeling U.S.-Japan Competition in Semiconductors." J. Policy Modeling 8 (Fall 1986): 305-26.

Flamm, Kenneth. "Forward Pricing versus Fair Value: An Analytical Assessment of 'Dumping' in DRAMs." In Trade and Protectionism, edited by Takatoshi Ito and Anne O. Krueger. Chicago: Univ. Chicago Press, 1993. (a)

- "Measurement of DRAM Prices: Technology and Market Structure." In Price Measurements and Their Uses, edited by Murray F. Foss, Marilyn E. Manser, and Allan H. Young. Chicago: Univ. Chicago Press, 1993. (b)

$\rightarrow$ Fudenberg, Drew, and Tirole, Jean. "Learning-by-Doing and Market Performance." Bell J. Econ. 14 (Autumn 1983): 522-30.

$\rightarrow$ Ghemawat, Pankaj, and Spence, A. Michael. "Learning Curve Spillovers and Market Performance." Q.J.E. 100 (suppl., 1985): 839-52.

Grossman, Gene M., and Helpman, Elhanan. Innovation and Growth in the Global Economy. Cambridge, Mass.: MIT Press, 1992.

$\rightarrow$ Gruber, Harald. "The Learning Curve in the Production of Semiconductor Memory Chips." Appl. Econ. 24 (August 1992): 885-94.

Irwin, Douglas A. "Trade Politics and the Semiconductor Industry." In The Political Economy of Protection, edited by Anne O. Krueger. Chicago: Univ. Chicago Press (for NBER), 1995, in press.

Irwin, Douglas A., and Klenow, Peter J. "High-Tech R \& D Subsidies: The Effects of Sematech.” Manuscript. Chicago: Univ. Chicago, 1994.

Kimura, Yui. The Japanese Semiconductor Industry: Structure, Competitive Strategies, and Performance. Greenwich, Conn.: JAI, 1988.

$\rightarrow$ Lieberman, Marvin B. "The Learning Curve and Pricing in the Chemical Processing Industries." Rand J. Econ. 15 (Summer 1984): 213-28.

$\rightarrow$ Lucas, Robert E., Jr. "On the Mechanics of Economic Development." J. Monetary Econ. 22 (July 1988): 3-42.

_. "Making a Miracle." Econometrica 61 (March 1993): 251-72.

National Advisory Committee on Semiconductors. A National Strategy for Semiconductors. Washington: Nat. Advisory Comm. Semiconductors, February 1992.

National Research Council. U.S.-Japan Strategic Alliances in the Semiconductor Industry: Technology Transfer, Competition, and Public Policy. Washington: Nat. Acad. Press, 1992.

Nye, William W. "Some Evidence on Firm-Specific Learning-by-Doing in Semiconductor Production." Discussion Paper no. 89-11. Washington: Dept. Justice, Econ. Analysis Group, July 1989.

Office of Technology Assessment. International Competitiveness in Electronics. Washington: Government Printing Office, 1983.

Okimoto, Daniel I. Between MITI and the Market: Japanese Industrial Policy for High Technology. Stanford, Calif.: Stanford Univ. Press, 1989.

Okimoto, Daniel I.; Sugano, Takuo; and Weinstein, Franklin B., eds. Competitive Edge: The Semiconductor Industry in the U.S. and Japan. Stanford, Calif.: Stanford Univ. Press, 1984. 
Organization for Economic Cooperation and Development. The Semiconductor Industry: Trade Related Issues. Paris: OECD, 1985.

$\rightarrow$ Romer, Paul M. "Increasing Returns and Long-Run Growth." J.P.E. 94 (October 1986): 1002-37.

Semiconductor Industry Association. The Effect of Government Targeting on World Semiconductor Competition. Cupertino, Calif.: Semiconductor Indus. Assoc., 1983.

$\rightarrow$ Spence, A. Michael. "The Learning Curve and Competition." Bell J. Econ. 12 (Spring 1981): 49-70.

Stapper, C. H.; Castrucci, P. P.; Maeder, R. A.; Rowe, W. E.; and Verhelst, R. A. "Evolution and Accomplishments of VLSI Yield Management at IBM." IBM J. Res. and Development 26 (September 1982): 532-45.

Stigler, George J. The Organization of Industry. Homewood, Ill.: Irwin, 1968.

Stokey, Nancy L. "The Dynamics of Industrywide Learning." In Essays in Honor of Kenneth J. Arrow, vol. 2, Equilibrium Analysis, edited by Walter P. Heller, Ross M. Starr, and David A. Starrett. New York: Cambridge Univ. Press, 1986.

$\longrightarrow \rightarrow-$ "Learning by Doing and the Introduction of New Goods." J.P.E. 96 (August 1988): 701-17.

Tilton, John E. International Diffusion of Technology: The Case of Semiconductors. Washington: Brookings Inst., 1971.

U.S. Department of Commerce. A Report on the U.S. Semiconductor Industry. Washington: Government Printing Office, September 1979.

Webbink, Douglas A. The Semiconductor Industry: A Survey of Structure, Conduct, and Performance. Washington: Fed. Trade Comm., January 1977.

Wilson, Robert W.; Ashton, Peter K.; and Egan, Thomas P. Innovation, Competition, and Government Policy in the Semiconductor Industry. Lexington, Mass.: Heath, 1980.

$\rightarrow$ Young, Alwyn. "Learning by Doing and the Dynamic Effects of International Trade." Q.J.E. 106 (May 1991): 369-405.

$\rightarrow \rightarrow$. "Invention and Bounded Learning by Doing." J.P.E. 101 (June 1993): 443-72.

$\rightarrow$ Zimmerman, Martin B. "Learning Effects and the Commercialization of New Energy Technologies: The Case of Nuclear Power." Bell J. Econ. 13 (Autumn 1982): 297-310. 